\title{
Revisiting Therapeutic Potentials of Ethanolic Extract of Curcuma longa L. rhizomes to Evaluate wound Healing Progression upon Topical Application of its Ointment
}

\author{
Tathagata Adhikary', Chowdhury Mobaswar Hossain², Sougata Mallick ${ }^{3}$, Samrat Paul', \\ Nisha Banerjee ${ }^{1}$, Piyali Basak ${ }^{1 *}$ \\ ${ }^{1}$ School of Bio-Science and Engineering, Jadavpur University, Kolkata, West Bengal, INDIA. \\ ${ }^{2}$ Department of Pharmaceutical Science \& Technology, Maulana Abul Kalam Azad University of Technology, West Bengal, Haringhata, \\ West Bengal, INDIA. \\ ${ }^{3}$ Department of Pharmacology, Bengal School of Technology (A College of Pharmacy), Sugandha, Chinsurah, Hooghly, West Bengal, \\ INDIA.
}

\begin{abstract}
Background and Aim: The goodness of turmeric is claimed traditionally but providing proper scientific data will not only support the statements making it more evident but will also search for possible ways to enhance its potential. The present study aims to extract the bioactive components from turmeric rhizomes to appraise its ability as a therapeutic agent. Methodology: Ethanolic extract and its doses were prepared for antioxidant and cytotoxicity assay. In-vivo study of wound healing activity of turmeric extract in the form of an ointment was evaluated upon its topical application in incision and excision wound models. The excised tissue samples were subjected to hematoxylin and eosin staining and content estimation of collagen biomarkers namely hydroxyproline, hexosamine and hexuronic acid. Results: DPPH assay showed the significant antioxidant activity of the extract with an $\mathrm{IC}_{50}$ value of $37.09 \pm 2.17 \mu \mathrm{g} / \mathrm{ml}$ while MTT assay revealed an $\mathrm{IC}_{50}$ value of $96.2 \pm 2.48 \mu \mathrm{g} / \mathrm{ml}$ against human breast cancer cell line MCF-7. In the incision and excision models, \% breaking strength of the wound and wound contraction rate in turmeric ointment treated mice w.r.t standard drug-treated mice are $109.28 \%$ and $80.5 \%$ while untreated mice exhibited a value of $77.75 \%$ and $52.74 \%$ respectively. Qualitative evaluation of the wound healing progression is depicted by the histopathological study of tissues. Indirect assessment of collagen content in tissues by quantitative estimation of collagen biomarkers aids to predict the progress of wound healing as their occurrence in increased amount confirmed the wound healing potential of turmeric and the prepared ointment base.
\end{abstract}

Key words: Cytotoxicity, Antioxidant, Wound healing, Collagen, Biomarkers, Histopathology.

\section{INTRODUCTION}

From ancient times, turmeric has shown its use as a spice and medicine. It has been cultivated in Southeast Asia and the Indian subcontinent because of the favorable environmental conditions such as the temperature of 20 to $30^{\circ} \mathrm{C}(68-86$ ${ }^{\circ} \mathrm{F}$ ) and a substantial amount of annual rainfall necessary for its survival. As of late, turmeric has been established to possess diverse pharmaceutical functions. Anti-inflammatory, anticancer, anti-aging, neuroprotection in Alzheimer's disease and wound healing are a few examples among many others. ${ }^{1-5}$ In pharmaceutics, extraction aims to separate therapeutically active components from the undesired plant matrix by selectively choosing solvents in the extraction protocol. The main bioactive
Submission Date: 05-08-2020; Revision Date: 02-10-2020; Accepted Date: 23-11-2020

DOI: 10.5530/ijper.55.1.19 Correspondence: Dr. Piyali Basak Assistant Professor, School of Bio-Science and Engineering, Jadavpur University, Kolkata-700032, West Bengal, INDIA.

Phone no: +91 9903303592 Email id: piyalibasak@gmail. com

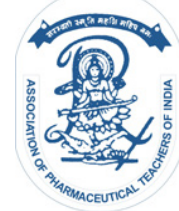

www.ijper.org 
compounds, the curcuminoids, are extracted using ethanol in this study. Free radicals including Reactive Oxygen Species (ROS) seemed to be responsible for triggering diseases such as asthma, Parkinson's and Alzheimer's diseases, diabetes and cancers. ROS also takes part in the aging process in humans. ${ }^{6,7}$ An antioxidant delays or inhibits oxidative damage due to its ability to trap free radicals. ${ }^{8} 9$ DPPH assay has been used here to check the anti-oxidative property of turmeric extract. Cytotoxicity of turmeric extract against normal cells (PBMC) and cancer cell line (MCF-7) is checked by MTT assay. ${ }^{10,11}$ Apart from its other biological activities, turmeric is often harnessed as a wound-healing agent. ${ }^{12}$ Researches on turmeric have proved its potentiality in different wound models. ${ }^{13}$ Curcumin from turmeric extract is reported to decrease inflammation and enhance the healing process in nasal wounds of rats. ${ }^{14}$ Among different delivery mechanisms investigated recently, one is turmeric agar composite films which showed an accelerated wound healing process. ${ }^{15}$ The formation of granulation tissue after an injury marks the beginning of the phase of new tissue formation. The most important structural constituent of granulation tissue is collagen which provides strength to the extracellular matrix..$^{16,17}$ Collagen fiber is composed of an amino acid proline as its basic component and thus hydroxyproline can act as a biochemical marker for collagen content in tissues indicating the progress of wound healing process. Other biochemical markers of collagen used here are hexosamine which is an amino sugar and hexuronic acid which acts as a cofactor in the collagen maturation process. ${ }^{18}$ Previous studies on wound healing using turmeric ointment do not take into account all these three biomarkers to validate its therapeutic activity. The proposed work established the biocompatibility of turmeric extract and prepared an ointment using it for assessing its wound healing activity in mice model. The progression of healing triggered by bioactive compounds of turmeric rhizomes was portrayed by correlating content-estimation of biochemical markers of collagen with histopathological images of respective tissues. The adopted methodology attempts an alternative approach for comparing quantitative analysis with the qualitative assessment of wound healing.

\section{MATERIALS AND METHODS \\ Extract preparation}

Dried and powdered rhizomes of Curcuma longa L. were macerated with ethanol in the ratio of 1:20 for $24 \mathrm{~h}$ which was followed by decoction with mild heating for $30 \mathrm{~min}$. Then it was left to stir for $6 \mathrm{~h}$ more and filtered using Whatman No.1 filter paper. The filtrate was concentrated and lyophilized to achieve the final sample of the crude extract. ${ }^{19}$ The lyophilized product was utilized in the formulation of ointment.

\section{Antioxidant activity - by DPPH assay}

A stock solution of ethanolic extract at $0.2 \mathrm{mg} / \mathrm{ml}$ concentration in $1 \%$ DMSO was made. Then it was serially diluted into four concentrations: 100, 50, 25 and $12.5 \mu \mathrm{g} / \mathrm{ml}$. A solution of $0.003 \% \mathrm{DPPH}$ in methanol was prepared. $20 \mu \mathrm{l}$ of test solutions were added to $3 \mathrm{ml}$ of DPPH solution and shaken vigorously. The mixture was kept at $37^{\circ} \mathrm{C}$ in the absence of light for $30 \mathrm{~min}$. Absorbance (Ab) was measured at $515 \mathrm{~nm}$ using a UV-visible spectrophotometer. The standard antioxidant used was citric acid and water was considered as the control. The scavenging ability of the test sample was determined using the equation given below: ${ }^{20}$

$$
\text { DPPH Scavenged }(\%)=\frac{(\text { Ab of control }-}{\text { Ab of control }} \times 100 \%
$$

where $\mathrm{Ab}$ is the absorbance at $\mathrm{t}=30 \mathrm{~min}$. All the tests were performed in triplicates and a calibration curve of $\%$ DPPH scavenged versus concentration was plotted. Values are presented as mean \pm S.D.

\section{Separation of peripheral blood mononuclear cells (PBMC)}

Fresh blood was collected in EDTA vials and a normal $0.9 \%$ saline solution was used for 1:3 dilution of whole blood. $3 \mathrm{ml}$ of HiSep LSM 1077 (a density gradient medium) was taken in a falcon tube and $12 \mathrm{ml}$ of diluted blood was layered carefully over it. The tube was centrifuged at $800 \times \mathrm{g}$ for $15 \mathrm{~min}$. This causes 4 layers to form. The topmost layer is of plasma thrombocytes and is followed by the white layer of PBMCs. ${ }^{21}$ This layer was taken carefully using a pipette without any RBCs or thrombocytes. It was washed 3 times using Roswell Park Memorial Institute (RPMI) 1640 cell culture medium and suspended in the same media with $10 \%$ FBS (fetal bovine serum, a growth supplement for cell culture media) and $2 \%$ penicillin-streptomycin.

\section{Cytotoxicity test - MTT assay}

PBMC was cultured in RPMI 1640 whereas MCF-7 (a breast cancer cell line that was first established in the institute Michigan Cancer Foundation-7) was cultured in DMEM. Cells were seeded on 96 well plates at $3 \times$ $10^{4}$ cells/well. After $24 \mathrm{hr}$, different wells were treated with different concentrations of turmeric extract in $1 \%$ 
DMSO. T.E1, T.E2, T.E3 and T.E4 correspond to 50, 100,200 and $400 \mu \mathrm{g} / \mathrm{ml}$ of turmeric extract respectively. Then the cells were incubated for $24 \mathrm{hrs}$. Subsequently, $20 \mu \mathrm{l}$ of MTT at $5 \mathrm{mg} / \mathrm{ml}$ concentration in PBS was added to each well and incubated for another 4 hrs. Following incubation, MT'T along with the media was pipetted out carefully and $100 \mu$ l of DMSO per well was transferred to solubilize the formed formazan. ${ }^{22}$ The absorbance was taken at $590 \mathrm{~nm}$ and \% viability was calculated as follows:

$$
\% \text { Viability }=\frac{\text { Absorbance of treated well }}{\text { Absorbance of untreated well }} \times 100 \%
$$

\section{Ointment preparation}

The ointment base i.e. the vehicle was prepared by mixing melted beeswax, liquid paraffin (heavy) and propylene glycol in the ratio of 1:3:2. Turmeric ointment was prepared by incorporating turmeric extract in the ointment base at $1 \%$ concentration. $0.1 \mathrm{gm}$ of each ointment was dispersed in $10 \mathrm{ml}$ of distilled water and the $\mathrm{pH}$ was recorded. The homogeneity of prepared ointments was evaluated by visually inspecting the presence/absence of lumps.

\section{Animal procurement}

Healthy Swiss Albino female mice weighing between 18-22 $\mathrm{g}$ were the experimental animals used here and procured from Saha Enterprise, Kolkata (Reg. No. 1828/PO/Bt/S/15/CPCSEA). The followed protocol of a randomized controlled trial has been approved by the Institutional Animal Ethics Committee (IAEC), Bengal School of Technology (approval code: 1726/ CPCSEA/IAEC/2019-007). The acclimatization of animals to laboratory conditions was done for 2 days before starting any experiment. The mice were housed in a polypropylene cage maintaining typical laboratory conditions of temperature $20-24^{\circ} \mathrm{C}$ and $12 \mathrm{hr}$ of lightdark cycle. A standard diet was provided with water ad-libitum throughout the experiment.

\section{Skin irritation test}

Six animals were divided into 2 groups $\mathrm{O}_{\mathrm{B}}$ and $\mathrm{O}_{\mathrm{T}}$ with 3 animals in each group. Dorsal hair was removed and on one side of the depilated back ointment was applied while the other side was kept blank serving as the control. Group $\mathrm{O}_{\mathrm{B}}$ received an ointment base and in group $\mathrm{O}_{T}$ turmeric ointment was given. The application of ointments was done once daily for 5 days. Dermal toxicity was checked by observing any occurrence of erythema or edema at the site of application of ointments.

\section{Wound creation and treatment protocol}

The dorsal fur of mice was removed and the region to be wounded is cleaned with $70 \%$ ethanol. The animals were divided into 2 groups $\mathrm{A}$ and $\mathrm{B}$ corresponding to incision and excision model respectively. Each group comprises 4 subgroups I, II, III and IV with 3 mice in each of them. Group I was challenged with no treatment given. Group II was the control group in which standard drug Nebasulf (a combination of bacitracin, neomycin and sulphacetamide sodium) was given. Group III and IV were treated with ointment base and turmeric ointment respectively. Prior to the wounding process, animals were anesthetized by intraperitoneal injection of ketamine and xylazine (dosing $60 \mathrm{mg} / \mathrm{kg}$ and $10 \mathrm{mg} / \mathrm{kg}$ respectively). Treatment was done daily and continued for 7 days.

\section{Incision wound model}

A paravertebral incision of $1 \mathrm{~cm}$ long was done using surgical blade No. 10 through the entire thickness of the skin on the depilated back of mice. After the incision, interrupted surgical sutures No. $1 / 0$ were applied to the parted skin at an interval of 0.5 centimeters. On the $5^{\text {th }}$ day, sutures were removed and on the $6^{\text {th }}$ day, the breaking strength of cured skin at the site of wound was measured.

\section{Measurement of breaking strength}

Under the anesthetic condition, two Allis forceps were fixed to the skin $0.5 \mathrm{~mm}$ away from the incision on each side of the injury. One forceps was held fixed at a position while the other forceps was freely hanged to which a container was attached (Figure 1). Water was added slowly to the container until the wound started to open and the amount of water in the container was noted down. The total weight required (i.e. weight of forceps + container + water) gave an indirect measure of the tensile strength of wounds and its \% breaking strength with respect to the control group (i.e. Group II) was calculated. ${ }^{23}$ Data are presented as mean \pm S.D.

$$
\% \text { breaking strength }=\frac{\text { Wound breaking strength of a group }}{\text { Wound breaking strength of control group }} \times 100 \%
$$

\section{Excision wound model}

Using forceps and pointed scissors circular excision wounds of about $8 \mathrm{~mm}$ diameter were created to the full thickness of the skin under aseptic conditions. The wound area was marked immediately on transparent polyethylene and the area was calculated. Observations were taken on the subsequent post wounding days and 


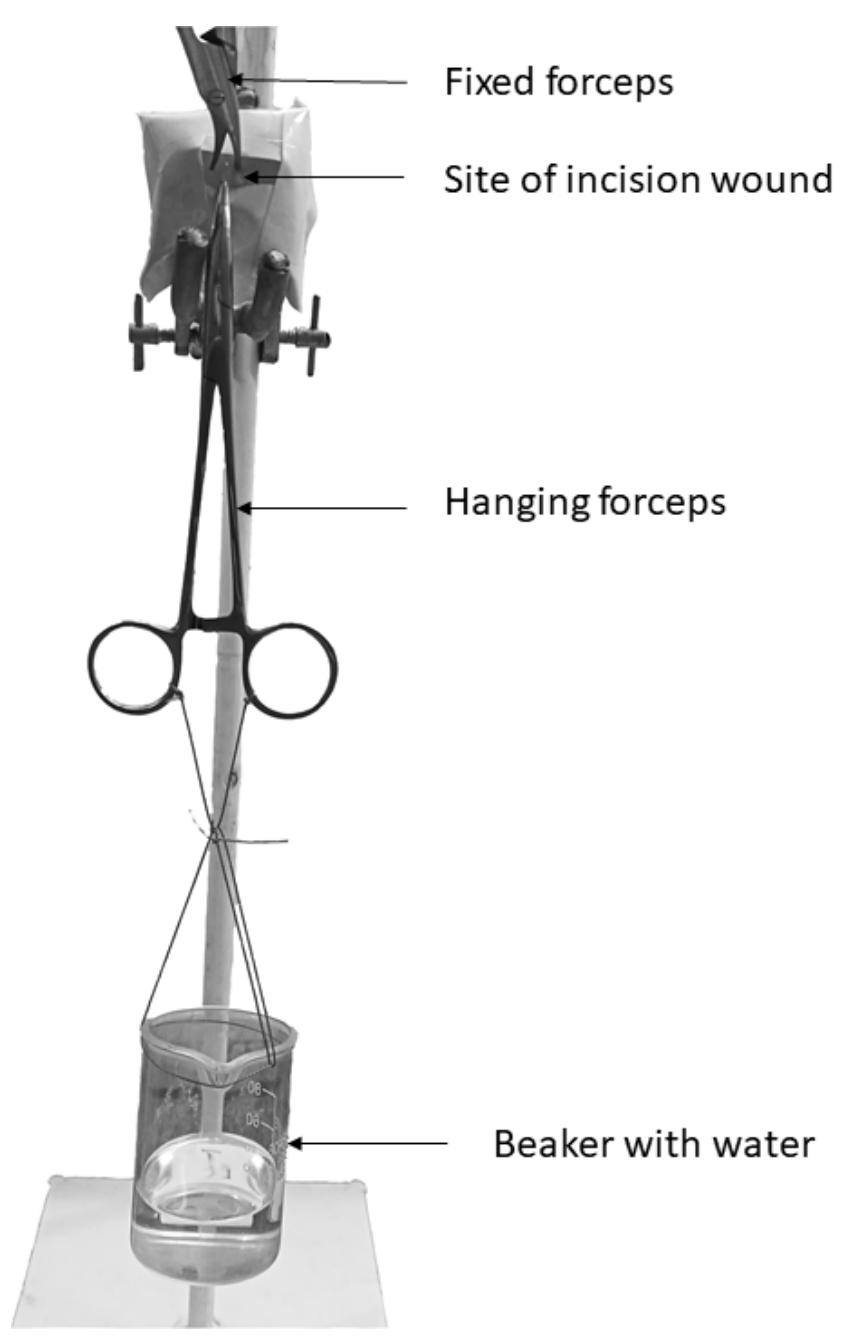

Figure 1: Experimental setup of the indirect measurement of tensile strength.

the percentage of wound closure was determined using the equation given below: ${ }^{24}$

$\%$ Wound contraction $=\frac{(\text { Initital wound size Specific day wound size })}{\text { Initial wound size }} \times 100 \%$

Measurements were done in triplicates and values were presented as mean \pm S.D. After 7 days, wound areas were excised and fixed in $10 \%$ formalin. Histopathological examination with $\mathrm{H}$ and $\mathrm{E}$ staining and biochemical parameters estimation were carried out by using the tissue specimens collected from the cured skin of each group of mice to determine the healing property of turmeric extract.

\section{Biochemical parameters estimation}

The excised wet granulation tissues were first defatted using acetone for 4 days. Acetone was changed two times in a day. After defatting, it was dried at $50^{\circ} \mathrm{C}$ for $24 \mathrm{hr}$ and kept in glass stoppered test tubes. After the addition of $1000 \mu \mathrm{l}$ of $6 \mathrm{~N} \mathrm{HCl}$ to each test tube, they were allowed to stand in a boiling water bath for $24 \mathrm{hr}$ to complete hydrolysis. The resulting product was then brought to room temperature. Neutralization of the excess of acid was done by $10 \mathrm{~N} \mathrm{NaOH}$ using phenolphthalein as an indicator. Distilled water was added to the neutral hydrolysate to achieve a concentration of $20 \mathrm{mg} / \mathrm{ml}$. It was stored and used for the content estimation of hydroxyproline, hexosamine and hexuronic acid. ${ }^{25}$

\section{Estimation of hydroxyproline}

L-hydroxyproline was used as a standard substrate to determine the hydroxyproline content in the tissues. $300 \mu \mathrm{l}$ of different samples i.e. tissue hydrolysates or standard solutions of L-hydroxyproline were mixed with $1 \mathrm{ml}$ of $0.01 \mathrm{M} \mathrm{CuSO}_{4}$. Then $1 \mathrm{ml}$ of $2.5 \mathrm{~N} \mathrm{NaOH}$ and $1 \mathrm{ml}$ of $6 \% \mathrm{H}_{2} \mathrm{O}_{2}$ was added to the mixture. The solutions were shaken frequently for $5 \mathrm{~min}$ and incubated in a shaker at $80^{\circ} \mathrm{C}$ for $10 \mathrm{~min}$. After cooling the solutions, $1.2 \mathrm{ml}$ of $3 \mathrm{~N} \mathrm{H}_{2} \mathrm{SO}_{4}$ was added and mixed thoroughly. Finally, $2 \mathrm{ml}$ of Ehrlich's reagent was added and the solutions were kept at $75^{\circ} \mathrm{C}$ for 15 min. Test tubes were then cooled by placing them in an ice bath. Absorbance was taken at $540 \mathrm{~nm}$ against the selected blank. ${ }^{26,27}$ The standard curve was prepared with L-hydroxyproline as the substrate and the amount of hydroxyproline in the samples was calculated using it. Data are expressed as mean \pm S.D.

\section{Estimation of hexosamine}

Glucosamine hydrochloride was used as a standard substrate to determine the hexosamine content in the tissues. The acid hydrolysates of different tissue samples or standard solutions of Glucosamine hydrochloride were subjected to deamination of hexosamine for determining the hexosamine content in the samples. In order to do deamination, $0.5 \mathrm{ml}$ of $5 \%$ sodium nitrite solution and $0.5 \mathrm{ml}$ of $33 \%$ of acetic acid solution was added to $0.5 \mathrm{ml}$ of test samples. The test tubes were shaken and allowed to stand for $10 \mathrm{~min}$ to accomplish the deamination process. The excess amount of nitrous acid was neutralized by adding $0.5 \mathrm{ml}$ of $12.5 \%$ ammonium sulfamate solution. The mixture was shaken frequently for $30 \mathrm{~min}$. This was followed by the indole reaction in which $2 \mathrm{ml}$ of $5 \% \mathrm{HCl}$ and $0.2 \mathrm{ml}$ of $1 \%$ solution of indole in ethanol were added to the sample solutions. The tubes were allowed to stand in boiling water bath for 5 min until a vivid orange color was seen with slight turbidity. Turbidity was removed by shaking after the addition of $1 \mathrm{ml}$ of ethanol. The absorbance of the solutions was determined by using a UV visible spectrophotometer at 492 and $520 \mathrm{~nm}$. The increase in the difference in absorbance values at 492 and 520 $\mathrm{nm}$ was considered as the measure of the amount of 
hexosamine present in the solutions. ${ }^{28}$ The hexosamine content in each tissue hydrolysate was calculated in $\mu \mathrm{g}$ per $\mathrm{mg}$ of tissue from the calibrated standard curve of Glucosamine hydrochloride. Data are expressed as mean \pm S.D.

\section{Estimation of hexuronic acid}

D-Glucurono-6, 3-lactone was used as a standard substrate to determine the hexuronic acid content in the tissues. Maintaining the temperature at $4^{\circ} \mathrm{C}, 2.5 \mathrm{ml}$ of 0.025 $\mathrm{M}$ Borax in concentrated sulfuric acid was added in stoppered test tubes. $0.2 \mathrm{ml}$ of the different tissue hydrolysates or standard solutions of D-Glucurono-6, 3-lactone were diluted to $0.5 \mathrm{ml}$ with distilled water. These $0.5 \mathrm{ml}$ of diluted solutions were layered carefully on the Borax-sulfuric acid mixture. After closing the test tubes they were shaken slowly and then vigorously while maintaining the temperature at $4^{\circ} \mathrm{C}$. Then the test tubes were immersed in a boiling water bath for $10 \mathrm{~min}$. Afterward, $0.1 \mathrm{ml}$ of $0.1 \%$ carbazole reagent in absolute ethanol was added to each test tube, shaken and kept in a boiling water bath for $15 \mathrm{~min}$. Color intensity was measured by reading the absorbance at $530 \mathrm{~nm}$ against a selected blank..$^{29}$ The content of hexuronic acid in the test solutions was estimated from the standard curve prepared using D-Glucurono- 6, 3-lactone. Data are expressed as mean \pm S.D.

\section{RESULTS AND DISCUSSION}

Ethanol has been chosen as the extracting solvent because of its high efficiency to solubilize phenols including curcumin and is comparatively more biocompatible than other solvents like methanol, acetone, etc. Maceration followed by decoction in the extraction process will aid in enhancing the release of phytochemicals from the plant matrix thereby increasing its concentration in the final filtered extract. After lyophilization, the product is recovered with the percentage yield of $9.12 \pm 0.82$.

\section{Antioxidant activity - by DPPH assay}

The majority of the synthetic antioxidants cause unsuitable side effects when consumed in-vivo. So, a trend to find naturally occurring non-toxic antioxidants to supplement processed food (for value addition and extension of the shelf life) or pharmaceuticals is becoming popular. It is a common belief that "green medicine" guarantees safety and effectiveness without any adverse side effects and thus can replace synthetic antioxidants that are being limited due to their cost and toxic nature. ${ }^{30}$ Although reactive oxygen species (ROS) play some important roles in cell signaling and immune responses (like their role in defense against invading bacteria), higher concentrations of ROS can cause oxidative stress during the healing process. Wound oxidative stress damaging biological molecules such as DNA, protein and lipids is known to get inhibited in the presence of antioxidants. Variation in the antioxidant activity of turmeric extract with the change in concentration is shown in Figure 2 and compared with the chosen standard citric acid. The $\%$ free radical scavenging activity for each concentration is calculated and the antiradical dose that causes $50 \%$ inhibition i.e. the $\mathrm{IC}_{50}$ value is estimated.

It was interpolated from Figure 2 that the $\mathrm{IC}_{50}$ of turmeric extract was $37.09 \pm 2.17 \mu \mathrm{g} / \mathrm{ml}$ while that of citric acid was $53.51 \pm 1.91 \mu \mathrm{g} / \mathrm{ml}$. This $\mathrm{IC}_{50}$ value claims turmeric to be a good antioxidant capable of inhibiting cellular damages due to ROS.

\section{Cytotoxicity test - MTT assay}

Turmeric extract seemed to increase the proliferation of PBMCs whereas selectively inhibiting the growth of breast cancer cell line MCF-7 (Figure 3). $\mathrm{IC}_{50}$ value for MCF-7 was $96.2 \pm 2.48 \mu \mathrm{g} / \mathrm{ml}$. This justifies that turmeric does not impart cytotoxic and cancerous effect in normal body cells, rather it counters cancerous proliferation due to its anticancer activity.

\section{Evaluation of Ointments}

The $\mathrm{pH}$ of the ointment base was noted as $6.84 \pm 0.07$ while that of the turmeric ointment was $6.96 \pm 0.09$. This is in the acceptable $\mathrm{pH}$ range and in good accordance with the fact that acidic environment accelerates wound healing by restricting infections (providing suitable antimicrobial environment), decreasing the toxicity of bacterial end products and promoting epithelization

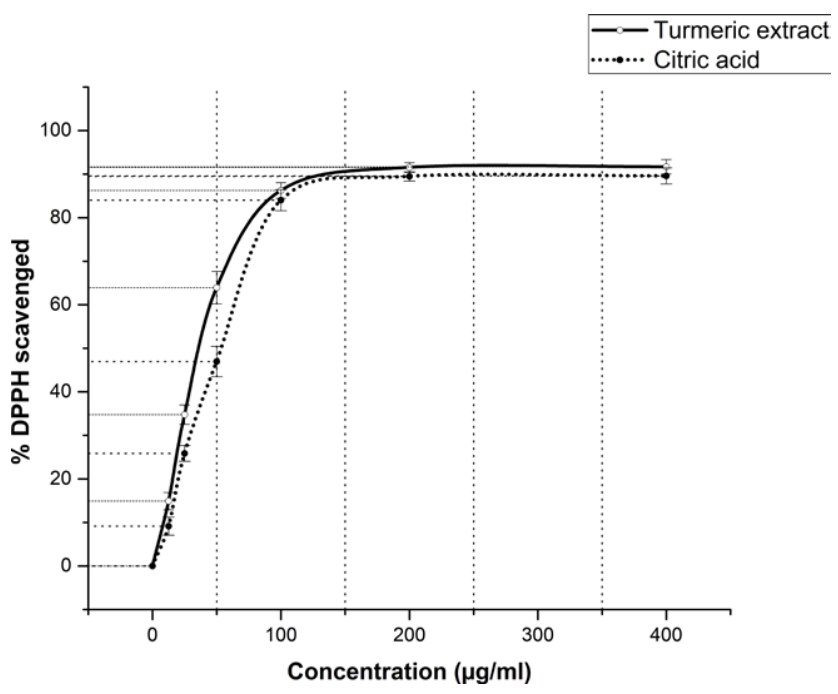

Figure 2: Antioxidant activity of ethanolic extract of Curcuma longa L. rhizomes and its comparison with citric acid. 


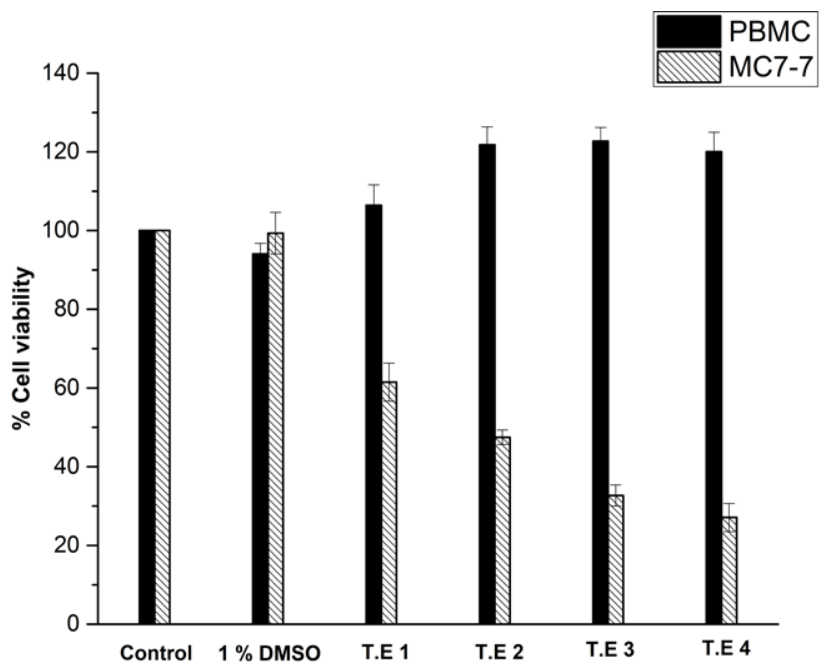

Figure 3: Comparative study of the dose-dependent effect of turmeric extract on PBMC and MCF-7.

and angiogenesis. ${ }^{31}$ Both the test ointments showed a high degree of homogeneity with the absence of any lumps.

\section{Skin irritation test}

Both groups $\mathrm{O}_{\mathrm{B}}$ and $\mathrm{O}_{\mathrm{T}}$ showed the absence of any irritation or inflammation on the entire dorsal region indicating the non-toxic nature of the prepared ointments on topical application.

\section{Incision wound model}

On the $6^{\text {th }}$ day, animals were observed and noted that those treated with turmeric ointment showed excellent healing of wounds compared to the other treated groups whereas group I (the untreated group) showed the lowest rate in healing process. Tensile strength is the force required to open up the incision. It indicates the resistance to breaking of the repaired tissues under tension and is equal to the maximum force applied per unit cross-sectional area of the repaired tissue before its breaking point (pictorial representation of indirect measurement of tensile strength is given in Figure 1). As the tensile strength increases, the quality of the repaired tissues becomes better.

Table 1 depicts the tensile strength (in grams) of different groups of animals. The breaking strength percentage of group II was considered as $100 \%$ and calculated for other groups with respect to group II. The application of turmeric ointment significantly increased the \% breaking strength to $109.28 \%$ (in group IV) while it exhibited a value of $77.75 \%$ and $95.62 \%$ in groups I and III respectively. This also indicates that the ointment base itself has some wound healing property while the prepared turmeric ointment is seen to impart better healing compared to the commercially available wound healing product used here. Beeswax used as a constituent in the composition of the ointment base has a mild wound healing property and is used in the treatment of burn wounds. ${ }^{32}$ It is also reported to exhibit antimicrobial activity against S. aureus, S. enterica, C. albicans, E. coli, B. subtilis and A. niger. ${ }^{33}$ Compared to the standard drug used in this study (in the form of powder), the ointment base covers the wound and acts as a dressing material by reducing the loss of proteins, electrolytes and fluid from the wound as well as minimizing infection at the site of injury.

\section{Excision wound model}

Monitoring the wounds daily by visual examination showed the absence of any kind of infection at the site of injury (Figure 4). After the treatment with any samples, the dressing was important to prolong their action giving sufficient time to the drugs to actively participate in the healing process. A similar dressing protocol was followed every day and all wounds received dressing at the same time.

Table 2 shows that among all the groups, turmeric ointment treated animals (i.e. group IV) showed increased enhancement in the progression of wound healing with wound contraction of $55.34 \%$ and $80.5 \%$ on day 4 and day 8 respectively whereas the challenged

\section{Table 1: Wound tensile strength of different groups} and comparison of their breaking strength.

\begin{tabular}{|c|c|c|}
\hline Group & Treatment & Breaking strength (in g) \\
\hline I & No treatment & $163.86 \pm 4.81$ \\
\hline II & Standard drug & $201.75 \pm 6.04$ \\
\hline III & Ointment base & $192.91 \pm 7.16$ \\
\hline IV & Turmeric ointment & $220.47 \pm 5.31$ \\
\hline
\end{tabular}

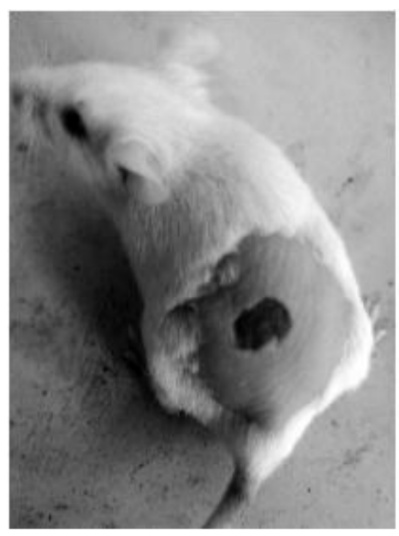

(a)

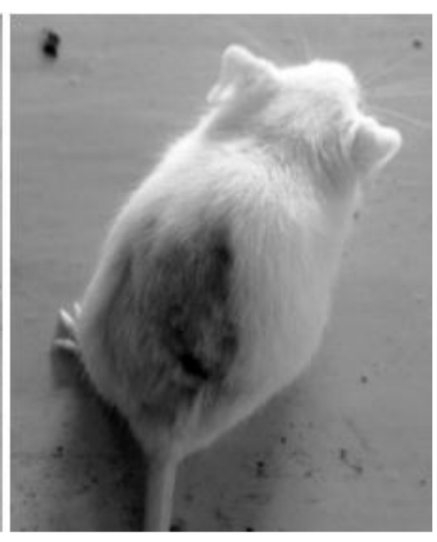

(b)
Figure 4: Progression of wound healing in turmeric ointment treated animals. A and B indicate the macroscopic appearance of wounded and healed (i.e. $8^{\text {th }}$ post wounding day) skin. 


\begin{tabular}{|c|c|c|c|c|}
\hline \multirow[t]{2}{*}{ Group } & \multirow[t]{2}{*}{ Treatment } & \multicolumn{3}{|c|}{ Wound area (in $\mathrm{mm}^{2}$ ) } \\
\hline & & Day 1 & Day 4 & Day 8 \\
\hline 1 & No Treatment & $48.67 \pm 0.89$ & $31 \pm 1.33$ & $23 \pm 0.67$ \\
\hline II & Standard drug & $51 \pm 0.67$ & $24.67 \pm 1.56$ & $12.67 \pm 0.89$ \\
\hline III & Ointment base & $51.33 \pm 1.56$ & $30.33 \pm 1.11$ & $18 \pm 0.67$ \\
\hline IV & $\begin{array}{l}\text { Turmeric } \\
\text { ointment }\end{array}$ & $53 \pm 0.67$ & $23.67 \pm 1.11$ & $10.33 \pm 0.44$ \\
\hline
\end{tabular}

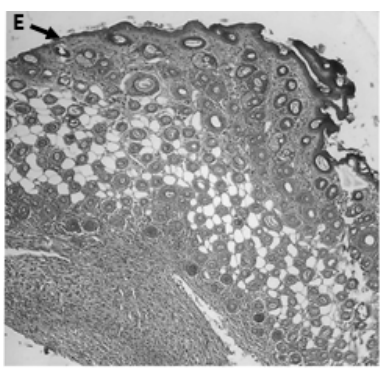

(a)

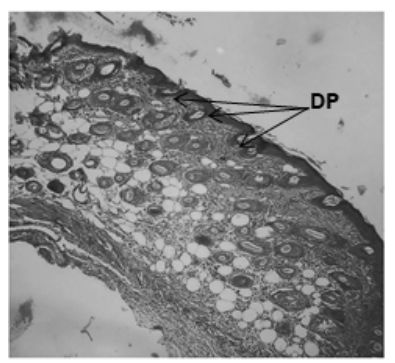

(c)

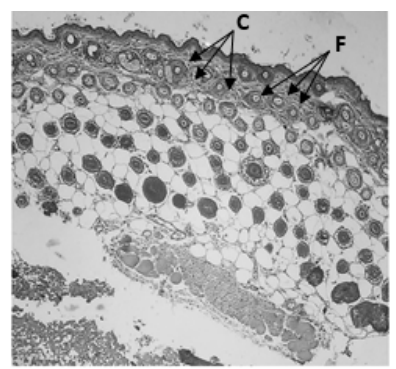

(b)

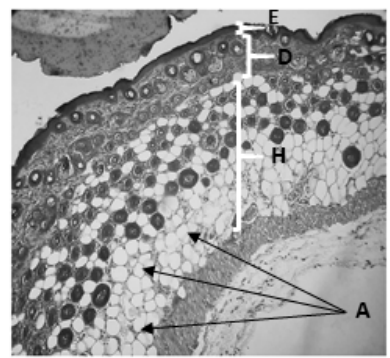

(d)
Figure 5: Histopathological examination of excised tissues stained with $\mathrm{H}$ and $\mathrm{E}$. (a), (b), (c) and (d) represent tissues from the group I, II, III and IV respectively. The markings E, D,

H, A, F, C and DP indicate epidermis, dermis, hypodermis, adipocytes, fibroblasts, collagen and dermal papillae respectively.

group (i.e. group I) exhibited a contraction of $36.3 \%$ and $52.74 \%$ only. The ointment base also showed some healing properties and its curative potential was quite comparable with the standard drug used here.

\section{Histopathological examination}

Figure 5 compares the tissues of different groups after 7 days of treatment. Tissue from the group I i.e. Figure 5 (a) showed delayed healing than other groups with scattered and unorganized collagen fibers. The epidermis (the darkest layer) is observed to be discontinuous with variation in its thickness. This migrating epithelium is comparatively thin than treated wounds establishing incomplete reepithelization. Moreover, it portrays a blurred boundary between the dermis and the basal layers of epidermis. There is an infiltration of cells (scattered inflammatory cells and fibroblasts) and less dense reticular layer (loosely packed collagen) indicates the untreated wounds to be in their late proliferative phase of wound healing with immature granulation tissue formation. The epidermis and dermis in Figure 5 (b) indicate its good formation with adequate vascularity and the absence of inflammation. Beneath the epidermis, the evenly stained region is the deposition of collagen fibers. Through the dermis, nuclei (stained in blue-purple) is less encountered in the reticular layer than the papillary layer of the dermis. Finer collagen fibers are present in the papillary layer which eventually aggregate into bundles of thick fibers forming the dense reticular layer. The hypodermis (the lightest layer supporting the dermis layer and attached to the muscle layer) consists mainly of adipocytes making up adipose tissue and its prominent appearance justifies healthy wound healing upon topical application of nebasulf. Although activation of adipocyte precursor cells and migration of adiponectin-expressing cells into the wound bed is witnessed in untreated wounds, adipogenesis occurred more in treated ones. Adipogenesis during the proliferative phase facilitates the recruitment and proliferation of fibroblasts leading to enhanced dermal healing. With the progress in wound healing, the provisional matrix with numerous cells in Figure 5 (a) is replaced by vascularized granulation tissue in Figure 5 (c). This is characterized by good collagen production and angiogenesis. The fibroblasts in the granulation tissue reconstruct the extra-cellular matrix and provide a scaffold for further tissue remodeling. The irregular border by dermal papillae increases the interaction area between the epidermis and dermis. The ointment base proved to aid the healing process. The dermal region of Figure 5 (d) exhibits mature granulation tissue as a result of significant fibrogenesis and neovascularization. There is a huge deposition of well-aligned collagen fibers which signs accelerated healing. Complete epithelium regeneration is observed in all the treated groups unlike the formation of loose crust in the untreated wound (Figure 5 a). The increased rate of wound contraction in turmeric ointment treated group is largely a consequence of improved reconstitution of epidermal covering which is evident from the epidermal thickening.

\section{Tissue biochemical parameters estimation}

Quantitative evaluation of the healing process can also be done by estimating the collagen content (as per the quantification of its biomarkers) in the tissues after 7 days of treatment (i.e. $8^{\text {th }}$ post wounding day). Collagen is the major extracellular protein in the granulation tissue. Its presence in the healing tissue provides strength and integrity to the matrix. Collagen fiber is composed 
of an amino acid proline as its basic component and thus hydroxyproline can act as a biochemical marker for collagen content in tissues indicating the progress of the wound healing process. Other collagen markers used here are hexosamine which is an amino sugar and hexuronic acid which acts as a cofactor in the collagen maturation process. Hydroxylation of amino acids lysine and proline is required for the formation of crosslinks in collagen matrix that gives strength to collagen. ${ }^{34}$ The deficiency of hexuronic acid reduces this hydroxylation process. A healthy wound healing process is characterized by a substantial amount of collagen formation, hence an increased amount of hydroxyproline, hexosamine and hexuronic acid accounts for a better healing process. ${ }^{35,36}$

\section{Estimation of hydroxyproline, hexosamine and hexuronic acid content}

The content of hydroxyproline, hexosamine and hexuronic acid in the tissues of different groups are calculated from the prepared standard curve. Data are expressed in $\mu \mathrm{g}$ equivalent of standards per $\mathrm{mg}$ of tissue.

Figure 6 reflects a significant difference in hydroxyproline content when compared between the challenged (i.e. Group I) and turmeric ointment treated (i.e. Group IV) groups. The content in group IV is $54.52 \pm 3.32 \mu \mathrm{g}$ per $\mathrm{mg}$ of tissue whereas group I exhibited a value of 43.55 $\pm 3.24 \mu \mathrm{g}$ per $\mathrm{mg}$ of tissue. This increase indicates the presence of more collagen and thus better healing process in group IV than others. Although only a slight change in hexosamine content is observed in the case of group II and group III, a typical rise is followed for group IV animals with hexosamine content of 21.41 $\pm 2.35 \mu \mathrm{g}$ equivalent of glucosamine hydrochloride per $\mathrm{mg}$ of tissue. Group I portrayed the least value
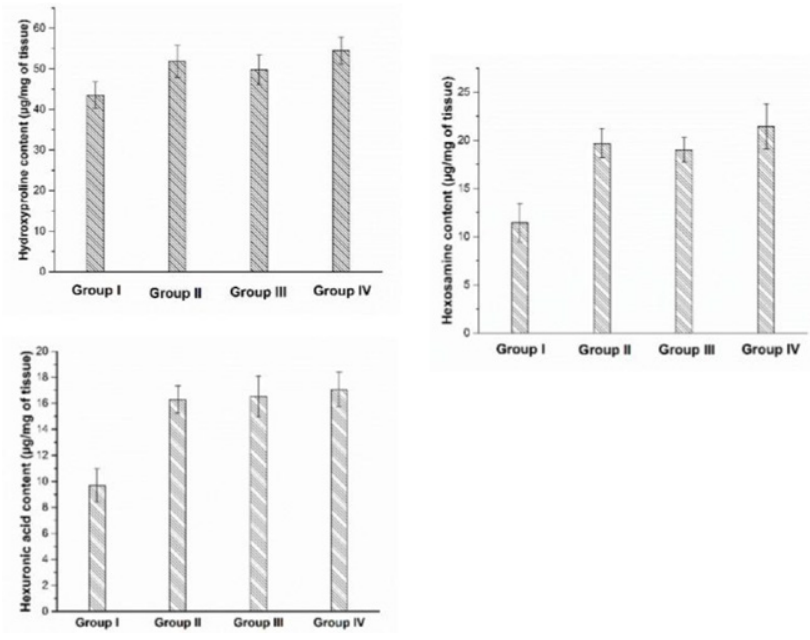

Figure 6: Comparison of hydroxyproline, hexosamine and hexuronic acid content among different groups. of $11.45 \pm 1.97$ among all the groups. Hexuronic acid content of group I animals is $9.68 \pm 1.28 \mu \mathrm{g}$ equivalent of DGlucurono-6, 3-lactone per mg of tissue which is much lower than group IV with a value of $17.06 \pm$ 1.33 justifying the higher healing potential of turmeric extract ointment than other treatments used here.

\section{CONCLUSION}

Turmeric is an excellent antioxidant and is not only biocompatible but also inhibits the growth of human cancer cells. It has been exploited as a wound-healing agent where both incision and excision wound models in mice confirmed its curative ability. $\mathrm{H}$ and $\mathrm{E}$ staining of tissues showed enhanced collagen formation in the turmeric ointment treated group. The extent of re-epithelialization, dermis and hypodermis formation, infiltration of cells (like fibroblasts) are clearly distinguishable among histological images of different treatment groups. Besides, the healing stage of a wound is reflected by the amount of hydroxyproline, hexosamine and hexuronic acid present in it. These collagen markers were found to be in substantially lower amounts in the untreated group of mice when compared to the treated ones. The ointment base itself has some wound healing property while the prepared turmeric ointment exhibited quite comparable results with the commercial product used here.

\section{ACKNOWLEDGEMENT}

The authors are thankful to TEQIP-III (Jadavpur University), Maulana Abul Kalam Azad University of Technology (West Bengal) and Bengal School of Technology and Management for providing their guidance and support.

\section{CONFLICT OF INTEREST}

The authors have no conflict of interest.

\section{ABBREVIATIONS}

DPPH: 2,2-diphenyl-1-picrylhydrazyl; $\quad$ IC $_{50}$ : The half-maximal inhibitory concentration; MTT: 3-(4,5-dimethylthiazol-2-yl)-2,5-diphenyl tetrazolium bromide; ROS: Reactive oxygen species; PBMC: Peripheral blood mononuclear cell; DMSO: Dimethyl Sulfoxide; S.D: Standard deviation; RBCs: Red blood cells; PBS: Phosphate buffer saline; H\&E: Hematoxylin and eosin. 


\section{REFERENCES}

1. Julie S, Jurenka M. Anti-inflammatory properties of curcumin, a major constituent. Altern Med Rev. 2009;14(2):141-53.

2. Ravindran J, Prasad S, Aggarwal BB. Curcumin and cancer cells: how many ways can curry kill tumor cells selectively?. The AAPS Journal. 2009;11(3):495-510.

3. Sikora E, Bielak-Zmijewska A, Mosieniak G, Piwocka K. The promise of slow down ageing may come from curcumin. Current Pharmaceutical Design. $2010=; 16(7): 884-92$.

4. Darvesh AS, Carroll RT, Bishayee A, Novotny NA, Geldenhuys WJ, DerSchyf CJV. Curcumin and neurodegenerative diseases: A perspective. Expert Opinion on Investigational Drugs. 2012;21(8):1123-40.

5. Panchatcharam M, Miriyala S, Gayathri VS, Suguna L. Curcumin improves wound healing by modulating collagen and decreasing reactive oxygen species. Molecular and Cellular Biochemistry. 2006;290(1-2):87-96.

6. Kanwar JR, Kanwar RK, Burrow H, Baratchi S. Recent advances on the roles of NO in cancer and chronic inflammatory disorders. Current Medicinal Chemistry. 2009;16(19):2373-94.

7. Chiavaroli V, Giannini C, DeMarco S, Chiarelli F, Mohn A. Unbalanced oxidant-antioxidant status and its effects in pediatric diseases. Redox Report. 2011;16(3):101-7.

8. Wayner DD, Burton GW, Ingold KU, Barclay LR, Locke SJ. The relative contributions of vitamin $\mathrm{E}$, urate, ascorbate and proteins to the total peroxyl radical-trapping antioxidant activity of human blood plasma. Biochimica et Biophysica Acta (BBA)-General Subjects. 1987;924(3):408-19.

9. Kedare SB, Singh RP. Genesis and development of DPPH method of antioxidant assay. Journal of Food Science and Technology. 2011;48(4):412-22.

10. Mosmann T. Rapid colorimetric assay for cellular growth and survival: Application to proliferation and cytotoxicity assays. Journal of immunological methods. 1983;65(1-2):55-63.

11. Marshall NJ, Goodwin CJ, Holt SJ. A critical assessment of the use of microculture tetrazolium assays to measure cell growth and function. Growth Regulation. 1995;5(2):69-84.

12. Enoch S, Leaper DJ. Basic science of wound healing. Surgery. 2005;23(2):37-42.

13. Tejada S, Manayi A, Daglia M, Nabavi SF, Sureda A, Hajheydari Z, et al. Wound healing effects of curcumin: A short review. Current Pharmaceutical Biotechnology. 2016;17(11):1002-7.

14. Denizot F, Lang R. Rapid colorimetric assay for cell growth and survival: Modifications to the tetrazolium dye procedure giving improved sensitivity and reliability. Journal of Immunological Methods. 1986;89(2):271-7.

15. Saraswathy N, Rohit R, Shanmugam K, Sozheeswari SC, Ramalingam P. A preliminary investigation of Turmeric-Agar composite film as bioactive wound dressing material on excision wound in rat model. Indian Journal of Natural Products and Resources. 2012; 3(2): 237-241

16. Sonnemann KJ, Bement WM. Wound repair: Toward understanding and integration of single-cell and multicellular wound responses. Annual Review of Cell and Developmental Biology. 2011;27:237-63.

17. Guo SA, DiPietro LA. Factors affecting wound healing. Journal of Dental Research. 2010;89(3):219-29.

18. Caetano GF, Fronza M, Leite MN, Gomes A, Frade MA. Comparison of collagen content in skin wounds evaluated by biochemical assay and by computer-aided histomorphometric analysis. Pharmaceutical Biology. 2016;54(11):2555-9

19. Basak DP, Adhikary T, Das P, Biswas S. Phytochemical analysis and comparative study of antibacterial effect of turmeric extracts using different solvent. In IOP Conf. Series Mat Sci Eng. 2018;410:012018.

20. Sharma OP, Bhat TK. DPPH antioxidant assay revisited. Food Chemistry. 2009;113(4):1202-5.

21. Mohanarao GJ, Mukherjee A, Banerjee D, Gohain M, Dass G, Brahma B et al. HSP70 family genes and HSP27 expression in response to heat and cold stress in vitro in peripheral blood mononuclear cells of goat (Capra hircus). Small Ruminant Research. 2014;116(2-3):94-9.

22. Simon A, Allais DP, Duroux JL, Basly JP, Durand-Fontanier S, Delage C Inhibitory effect of curcuminoids on MCF-7 cell proliferation and structureactivity relationships. Cancer letters. 1998;129(1):111-6.

23. Jha RK, Garud N, Nema RK. Excision and incision wound healing activity of flower head alcoholic extract of Sphaeranthus indicus Linn. in albino rats. Global Journal of Pharmacology. 2009;3(1):32-7.

24. Rashed AN, Afifi FU, Disi AM. Simple evaluation of the wound healing activity of a crude extract of Portulaca oleracea L.(growing in Jordan) in Mus musculus JVI-1. Journal of Ethnopharmacology. 2003;88(2-3):131-6.

25. Alper JC, Welch EA, Maguire P. Application of moist wound healing to the gerontologic population. Age. 1986;9(4):105-9.

26. Bergman I, Loxley R. Two improved and simplified methods for the spectrophotometric determination of hydroxyproline. Analytical Chemistry. 1963;35(12):1961-5.

27. Chaudhari M, Mengi S. Evaluation of phytoconstituents of Terminalia arjuna for wound healing activity in rats. Phytotherapy Research: An International Journal Devoted to Pharmacological and Toxicological Evaluation of Natural Product Derivatives. 2006;20(9):799-805.

28. Chen WC, Liou SS, Tzeng TF, Lee SL, Liu IM. Wound repair and antiinflammatory potential of Lonicera japonica in excision wound-induced rats. BMC Complementary and Alternative Medicine. 2012;12(1):226.

29. Murthy S, Gautam MK, Goel S, Purohit V, Sharma H, Goel RK. Evaluation of in vivo wound healing activity of Bacopa monniera on different wound model in rats. BioMed Research International. 2013.

30. Hoffmann D. Medical herbalism: The science and practice of herbal medicine Simon and Schuster. 2003

31. Naranje N, Urewar C, Nandanwar P, Deliya V, Makkad J. Acidic environment and wound healing: A review. Wounds: A Compendium of Clinical Research and Practice. 2015;27(1):5-11.

32. Bayir Y, Un H, Ugan RA, Akpinar E, Cadirci E, Calik I, et al. The effects of Beeswax, Olive oil and Butter impregnated bandage on burn wound healing. Burns. 2019;45(6):1410-7.

33. Fratini F, Cilia G, Turchi B, Felicioli A. Beeswax: A minireview of its antimicrobial activity and its application in medicine. Asian Pacific Journal of Tropical Medicine. 2016;9(9):839-43.

34. Ricard-Blum S. The collagen family. Cold Spring Harbor Perspectives in Biology. 2011;3(1):a004978.

35. Forrest L. Current concepts in soft connective tissue wound healing. British Journal of Surgery. 1983;70(3):133-40

36. Kavitha $\mathrm{CCl}$, Indira $\mathrm{G}$. Wound healing activity of ethanolic extract of roots of Morinda pubescens JE Smith. Journal of Pharmacognosy and Phytochemistry. 2016;5(3):43-6. 


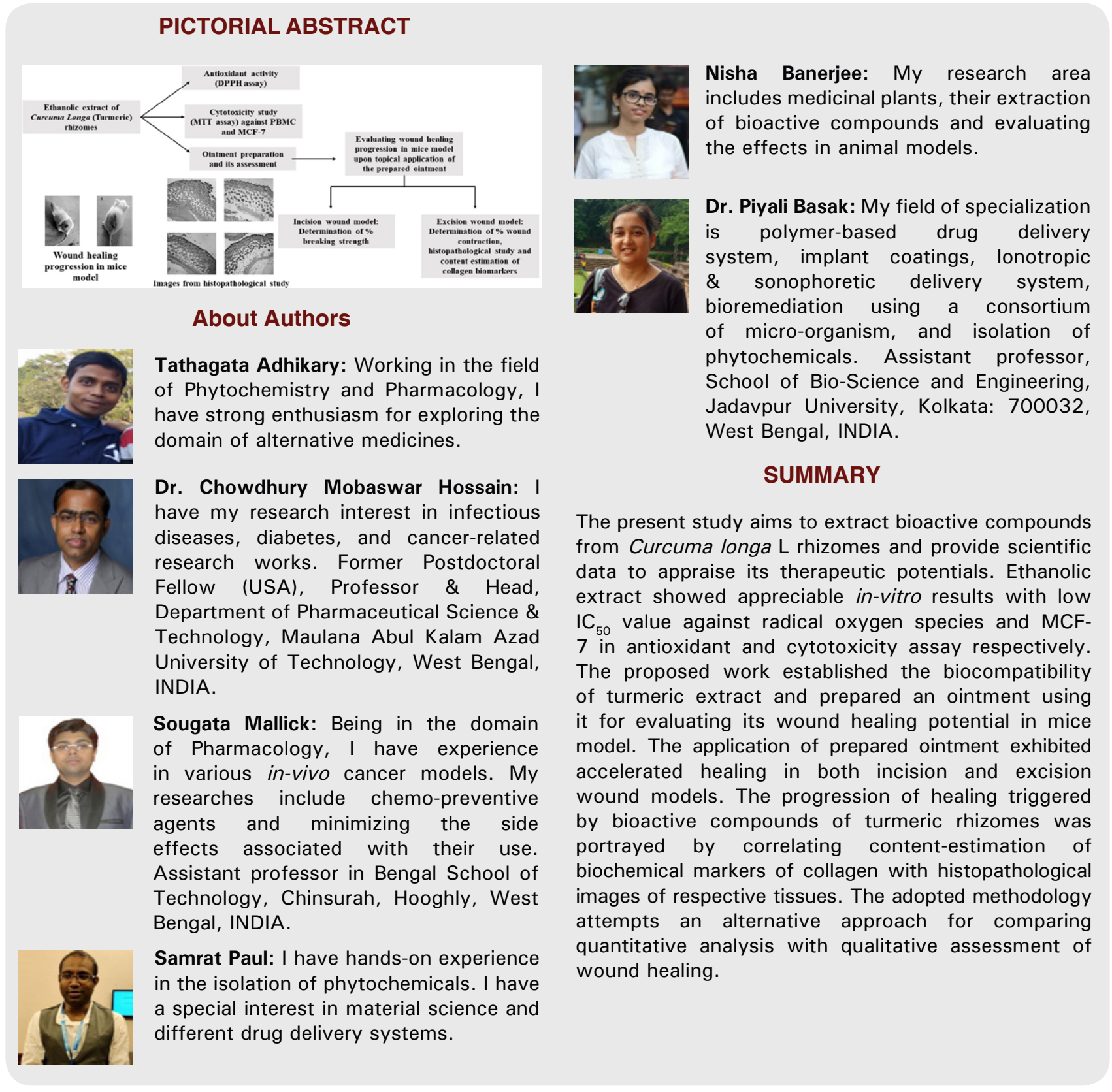

Cite this article: Adhikary T, Hossain CM, Mallick S, Paul S, Banerjee N, Basak P. Revisiting Therapeutic Potentials of Ethanolic Extract of Curcuma longa L. rhizomes to Evaluate wound Healing Progression upon Topical Application of its Ointment. Indian J of Pharmaceutical Education and Research. 2021;55(1):174-83. 